University of Nebraska - Lincoln

DigitalCommons@University of Nebraska - Lincoln

Faculty Publications, Department of Psychology

Psychology, Department of

June 2002

\title{
Factors influencing children to self-disclose sexual abuse
}

\author{
Mary L. Paine \\ University of Nebraska-Lincoln \\ David J. Hansen \\ Univertsity of Nebraska-Lincoln, dhansen1@unl.edu
}

Follow this and additional works at: https://digitalcommons.unl.edu/psychfacpub

Part of the Psychiatry and Psychology Commons

Paine, Mary L. and Hansen, David J., "Factors influencing children to self-disclose sexual abuse" (2002). Faculty Publications, Department of Psychology. 59.

https://digitalcommons.unl.edu/psychfacpub/59

This Article is brought to you for free and open access by the Psychology, Department of at DigitalCommons@University of Nebraska - Lincoln. It has been accepted for inclusion in Faculty Publications, Department of Psychology by an authorized administrator of DigitalCommons@University of Nebraska - Lincoln. 
Published in Clinical Psychology Review 22 (2002), pp. 271-295. Copyright (C 2001 Elsevier Science Ltd. Used by permission. http://www.sciencedirect.com/science/journal/02727358

\title{
Factors influencing children to self-disclose sexual abuse
}

\author{
Mary L. Paine and David J. Hansen \\ Department of Psychology, University of Nebraska-Lincoln \\ Submitted January 2000; revised February 2000; accepted April 2000
}

\begin{abstract}
Self-disclosure by victims of child sexual abuse (CSA) is critical to initiate legal and therapeutic intervention. Unfortunately, research indicates that lengthy delays in disclosure and even nondisclosure are common. A comprehensive review of the clinical and research literature on CSA and an overview of related bodies of literature was conducted. Areas addressed include the context of sexual abuse as it relates to disclosure, the context and elements of children's disclosures, motivational factors inhibiting disclosure, and models of the disclosure process. Ancillary and analogue research on secrecy and disclosure are also reviewed. Implications for future research and practice are discussed.
\end{abstract}

Keywords: Child sexual abuse, Disclosure, Secrecy

\section{Introduction}

A child's self-disclosure of sexual abuse is a critical component in initiating intervention to halt the abuse, address its immediate effects, and decrease the likelihood of negative long-term outcome. Professionals working with perpetrators, families, and victims of child sexual abuse (CSA) have identified numerous internal and external factors that inhibit children from disclosing their abuse (Furniss, 1991; Gomes-Schwartz, Horowitz, \& Cardarelli, 1990; Sorenson \& Snow, 1991; Summit, 1983). Furthermore, the process by which perpetrators gain and maintain their victim's compliance and silence frequently places the child in the role of a coconspirator acting to conceal their own abuse (Berliner \& Conte, 1990; Furniss, 1991; German, Habenicht, \& Futcher, 1990; Summit, 1983).

Many adult survivors never disclosed or delayed disclosing their abuse for years, attesting to the extreme difficulty of revealing the secret (Finkelhor, Hotaling, Lewis, \& Smith, 1990; Russell, 1986; Sauzier, 1989). The difficulty victims experience in revealing their abuse is also 
evident in the crisis that often occurs following disclosure or discovery of the abuse (Berliner \& Conte, 1995; Cristiansen \& Blake, 1990). Research consistently indicates that most child victims delay disclosing for significant periods of time and many had never disclosed at the time their abuse was discovered in some other manner (Gomes-Schwartz et al., 1990; Kelley, Brant, \& Waterman, 1993; Sorenson \& Snow, 1991). Children who experience abuse over longer periods of time are at greater risk of negative long-term outcome (Arata, 1998; Conte \& Schuerman, 1987; Kendall-Tackett, Williams, \& Finkelhor, 1993).

Numerous emotional and behavioral indicators of CSA have been identified, however, none has been established as diagnostic or conclusive (Kendall-Tackett et al., 1993). Due to the covert nature of CSA and the frequent absence of physical evidence (Sauzier, 1989), the onus of initiating intervention to end the abuse through self-disclosure often falls upon the child. Efforts in the United States to identify victims of child abuse and promote early intervention include public awareness campaigns, prevention education, and enactment of mandatory reporting statutes nationwide. All 50 states have reporting statutes that require all relevant professionals to report cases of known or suspected abuse to the appropriate investigatory agency. The reporting statutes in many states require all adults to report known or suspected abuse.

Reports of child maltreatment increased dramatically subsequent to the enactment of mandatory reporting statutes. Despite the marked increase in reports of suspected abuse, results of numerous empirical studies indicate significant numbers of professionals mandated to report known or suspected cases of abuse fail to do so (e.g., Faller, 1985; Hansen et al., 1997; Pope, Tabachnik, \& Keith-Spiegel, 1987; Swoboda, Elwork, Sales, \& Levine, 1987). Consistent with these findings, a study of public attitudes toward child abuse in one state revealed that threequarters of the respondents were aware of their obligation to report cases of child abuse to the authorities; however, only one-third of the respondents possessing knowledge of a case of child abuse indicated that they had actually reported the abuse to the authorities (Dhooper, Royse, \& Wolfe, 1991). These findings underscore the critical nature of the child victim's disclosure.

A child's ability and willingness to report their victimization plays a critical role in legal and therapeutic intervention. Investigations of abuse have frequently been impeded when children fail to disclose abuse, deny abuse that has occurred, or recant a prior disclosure. Failure to make a clear disclosure at the time of a formal investigation is likely to result in the finding that the suspicions of abuse are "unfounded" or "unsubstantiated," therefore, resulting in termination of the investigation. The child subsequently remains at risk of continued abuse, risk that may now be heightened by the negative consequences of the child's attempt at disclosure, thereby decreasing the likelihood of future attempts to disclose (Faller, 1985). Furthermore, the investigatory and legal processes almost inevitably necessitate that the child make repeated disclosures of abuse to multiple individuals during a process that may span months or even years. Repeated disclosures may also be necessitated by the disbelief of family members or trusted adults to whom the child discloses and/or the failure of these individuals to take effective action to halt the abuse (Sauzier, 1989; Sorenson \& Snow, 1991). In an archival study of confirmed cases of CSA, records revealed reporting failure on the part of the confidant in 20 of 83 cases of disclosure by child victims (Paine \& Hansen, 2001). Other factors, such as photographic evidence or 
disclosure by other victims, eventually resulted in investigation and confirmation of the abuse. Such findings indicate that it is not enough to educate children regarding acts that constitute abuse and instruct them to tell. Efforts must be made to increase the responsiveness of others to children's disclosures of abuse.

The importance of a child's self-disclosure of sexual abuse extends beyond the individual child and her or his family. Research indicates that sexual offenders commit many more crimes against children than those for which they have been investigated and/or convicted (Elliott, Browne, \& Kilcoyne, 1995; Groth, Longo, \& McFadin, 1982). A child's self-disclosure of abuse may lead to identification of an offender who poses a threat to other children, resulting in therapeutic and legal interventions to prevent and/or halt the sexual victimization of others.

Despite the sizeable body of literature on CSA, many researchers and clinicians have identified the need for increased knowledge regarding the circumstances of children's disclosures (Daro, 1994; Keary \& Fitzpatrick, 1994; Steward, Bussey, Goodman, \& Saywitz, 1993). This article contains a critical examination of the clinical and research literature relevant to children's self-disclosure of sexual abuse to better understand the disclosure process. More specifically, this literature review addresses the context of sexual abuse as it relates to disclosure, the context and elements of children's disclosures, motivational factors inhibiting disclosure, and models of the disclosure process. Related ancillary and analogue research on secrecy and disclosure, as well as implications for future research and practice, are also discussed.

\section{The context of sexual abuse as it relates to disclosure}

\subsection{Abuse and victim characteristics}

Results of a large study revealed that children at the extremes of the spectrum of severity were least likely to disclose their sexual victimization (Gomes-Schwartz et al., 1990). Fiftyfour percent of children subjected to intercourse did not disclose their abuse. At the opposite end of the spectrum of severity, 50\% of those who experienced attempted sexual activity or noncontact forms of sexual abuse did not disclose. Arata (1998) found an inverse relationship between disclosure and severity of abuse. Subjects reporting contact sexual abuse were significantly less likely to disclose than those reporting noncontact sexual abuse.

Children's abuse disclosures have been described as being: (a) purposeful or accidental; (b) spontaneous or prompted/elicited; and (c) explicit or vague (Bybee \& Mowbray, 1993; Furniss, 1991; Kelley et al., 1993; Sauzier, 1989; Sorenson \& Snow, 1991). These descriptors correspond respectively with three dimensions: (a) intent; (b) spontaneity; and (c) detail. There is considerable research that reveals age-related differences in the dimensions of intent and detail. Findings of some studies suggest the disclosures of younger children tend to be vague (Faller, 1988; Mordock, 1996). In contrast, Bybee and Mowbray (1993) noted that $70 \%$ of children age 5 and under provided explicit disclosures of sexual abuse experienced, while only $34 \%$ of those above the age of 5 made explicit disclosures. However, it appears that the differences in the latter study may be attributed to differences in interview techniques. Specifically, the increase 
in explicit disclosures may have resulted from the use of anatomical dolls during investigative interviews with the younger children. Preschool age children appear more likely to disclose accidentally and in response to a precipitating event (Campis, Hebden-Curtis, \& Demaso, 1993; Mian, Wehrspann, Klajner-Diamond, Labaron, \& Winder, 1986; Sorenson \& Snow, 1991), while older children are more likely to disclose in a purposeful manner (Campis et al., 1993; Sorenson \& Snow, 1991). Purposeful disclosure may be inhibited in children who are developmentally immature or delayed due to limited knowledge of social norms and behaviors that constitute abuse (Bussey \& Grimbeek, 1995; Campis et al., 1993).

Preschool age children have been observed to be significantly less likely to disclose during the context of formal investigation (Dipietro, Runyan, \& Fredrickson, 1997; Keary \& Fitzpatrick, 1994). Gries, Goh, and Cavanaugh (1996) found younger children were more likely to require a second interview before disclosing. Communicative competency and the rigorous guidelines employed in abuse investigations have been cited as obstacles to disclosure for developmentally immature or delayed children and those with communicative disorders (Saywitz, Nathanson, \& Snyder, 1993).

The literature suggests disproportionately higher numbers of children with disabilities are victims of sexual abuse (Browning \& Boatman, 1977; Goldman, 1994; Sullivan \& Knutzon, 2000). Sullivan and Knutzon (2000) found that sexual abuse for children with education-related disabilities (i.e., visual, hearing, speech/language, or health impairment; mental retardation; learning or physical disability; behavior disorder) occurred at a significantly higher rate than for children without a disability. In addition, Sullivan and Knutzon found that children with disabilities were more likely to be maltreated in multiple ways over multiple episodes. Differences by type of disability were also found, with those identified as having behavior disorder the most likely to experience sexual abuse, followed by those with mental retardation. The limited research and clinical literature indicates that children with disabilities are likely to encounter special problems disclosing their abuse. These impediments may include physical and social isolation related to their disability, impaired ability to communicate, and increased dependency and vulnerability (Goldman, 1994; Saywitz et al., 1993). In addition to the difficulties they may experience communicating their abuse to others, the disclosures of disabled children (especially those with cognitive impairments) are less likely to be viewed as credible (Saywitz et al., 1993).

Studies have yielded mixed findings on the relationship between the gender of a victim and disclosure of sexual abuse. A few studies have found gender and disclosure to be unrelated (Bybee \& Mowbray, 1993; DiPietro et al., 1997; Sauzier, 1989). However, a variety of research suggests that underreporting is a significant problem among boys (Violato \& Genius, 1993). Research suggests that boys are more hesitant and unlikely to disclose than girls (Bolton, Morris, \& MacEachron, 1989; Finkelhor, 1990; Gries et al., 1996; Keary \& Fitzpatrick, 1994; Lamb \& Edgar-Smith, 1994; Lynch, Stern, Oates, \& O'Toole, 1993; Reinhart, 1987; Watkins \& Bentovim, 1992). The trend may increase with age, as adolescent boys have been observed to be least likely to report their sexual victimization (Hecht \& Hansen, 1999; Lamb \& Edgar-Smith, 1994; Watkins \& Bentovim, 1992). Faller (1989) has noted that boys reluctance to disclose emanates from "the fact boys are socialized not to reveal doubts, weaknesses, and fears, and 
the fact that, since most of the abusers are male, boys have the additional taboo of homosexuality to overcome if they tell" (p. 282). Additionally, boys sexually abused by a female are faced with societal norms that endorse and even glorify "older woman/young boy" sexual relationships and fantasies (Hecht \& Hansen, 1999; Jennings, 1993). While incidence of reported sexual abuse by females is quite low in comparison to their male counterparts, it is commonly believed that incidence of female offending is significantly underestimated due to underreporting of their offenses (Elliott, 1993; Jennings, 1993).

Though there is limited clinical and research literature on disclosure of sexual abuse by child victims belonging to ethnic and cultural minorities, it is evident that these individuals are likely to encounter additional obstacles to disclosure. In a discussion of the literature on cultural aspects of family violence, Kazarian and Kazarian (1998) identified numerous factors associated with vulnerability to violence and obstacles to utilization of services. Those cultural factors particularly relevant to disclosure of sexual abuse include language barriers, social isolation, concerns related to immigration status or deportation, discrimination, lack of knowledge and familiarity with community support systems, absence of culture specific services, racism, and cultural insensitivity in mainstream programs. Variations in belief systems and value orientations related to one's cultural background have also been identified as factors influencing an individuals willingness to self-disclose sexual abuse (Futa, Hsu, \& Hansen, in press; Toukmanian \& Brouwers, 1998). For example, Toukmanian and Brouwers (1998) identified an individualistic vs. collectivistic value orientation as one of several differences that might influence one's willingness to self-disclose. More specifically, children raised within cultures espousing collectivistic values may be more hesitant to disclose their abuse due to heightened concerns regarding the negative impact their disclosure will bring upon their family and ancestors (Futa et al., in press; Toukmanian \& Brouwers, 1998). Finally, cultural attitudes toward purity-virginity and/or stigmatization of those sexually victimized greatly compound disclosure for some (Kazarian \& Kazarian, 1998; Muntarbhorn, 1996). The cultural factors influencing an individual's willingness to disclose are directly relevant to the response of their family to their disclosure and the family's willingness to seek legal and/or therapeutic intervention.

\subsection{Victim-perpetrator relationship}

Regardless of a child's gender, studies consistently indicate that the victim-perpetrator relationship in cases of CSA is most often a familiar one (Berliner \& Conte, 1995; Elliott et al., 1995; Faller, 1989; Finkelhor et al., 1990; Gomes-Schwartz et al., 1990; Ligezinska, Firestone, et al., 1996; Sorenson \& Snow, 1991). There is, however, considerable variation across studies in the rates of intrafamilial, extrafamilial, and stranger abuse. This variation appears to be attributable, in large part, to sampling differences. Studies using victim samples reflect lower rates (0-19.5\%) of sexual abuse by strangers (Berliner \& Conte, 1995; Faller, 1989; GomesSchwartz et al., 1990; Ligezinska, McIntyre, Ensom, \& Wells, 1996; Sorenson \& Snow, 1991) than do those employing a random sample (21-40\%) (Finkelhor et al., 1990) or a perpetrator sample (34\%) (Elliott et al., 1995). 
The victim-perpetrator relationship is not only most often a familiar one, but is also often an emotionally close and significant one. The individual perpetrating the abuse is often a parent or parent-figure (Berliner \& Conte, 1995; Faller, 1989; Gomes-Schwartz et al., 1990; Sorenson \& Snow, 1991). The perpetrator is frequently in a position of power and authority over the child and/or charged with providing for the child's care (Berliner \& Conte, 1995; Elliott et al., 1995; Sorenson \& Snow, 1991). In a study that explored the process of sexual victimization from the perspective of the child victim, the authors noted the child's relationship with their perpetrator filled significant deficits in the child's life in many cases (Berliner \& Conte, 1990). Most of the children described their relationship with the perpetrator as positive. Many expressed ambivalent feelings toward the individual perpetrating the abuse. "Over half said that they loved him, liked him, needed or depended on him” (Berliner \& Conte, 1990 p. 32). Nearly half also reported they hated him.

Clinicians have observed children who are sexually abused by a close family member are particularly hesitant to disclose their abuse (Furniss, 1991; Rieser, 1991; Summit, 1983). Research findings consistently indicate that children abused by a close family member are less likely to report their abuse than those abused by a stranger (Arata, 1998; Berliner \& Conte, 1990; DiPietro et al., 1997; Mendelsohn, 1994; Sauzier, 1989; Sorenson \& Snow, 1991). This finding is particularly important as research also suggests that the longer children are abused, the more hesitant they may be to disclose their abuse (Arata, 1998; Mendelsohn, 1994).

\subsection{Perpetrator's selection and grooming process}

The clinical and research literature regarding the process by which offenders select and groom their victims further illuminates the basis for the ambivalent feelings victims often have for their perpetrators. In addition, this literature provides insight into the reasons many victims delay disclosure or never disclose their abuse. In a study of 72 adult male inmates incarcerated for CSA, subjects identified a preference for abusing their own children and/or choosing "passive, quiet, troubled, lonely children from single parent or broken homes" (Budin \& Johnson 1989, p. 79). Similarly, perpetrators in a specialized treatment program indicated that they generally targeted children who were quiet and withdrawn and/or appeared vulnerable because of their age or friendliness (Conte, Wolfe, \& Smith, 1987). Perpetrators frequently seek out children who are particularly trusting (Conte et al., 1987) and work proactively to establish a trusting relationship with them before assaulting them (Budin \& Johnson, 1989; Conte, Wolfe, \& Smith, 1989; Elliott et al., 1995; Warner-Kearney, 1987). Not infrequently, this extends to establishing a trusting relationship with the victim's family as well (Elliott et al., 1995), affording the perpetrator greater access to and control of the child.

\subsection{Strategies used to gain and maintain compliance and secrecy}

The methods employed by perpetrators to gain and maintain their victim's compliance and silence have been well documented in the research and clinical literature (Berliner \& Conte, 1990; Budin \& Johnson, 1989; Christiansen and Blake, 1990; Conte et al., 1987; Elliott et al., 1995; Furniss, 1991; Kaufman, Hilliker, \& Daleiden, 1996; Lyon, 1996; Singer, Hussey, \& Strom, 1992; 
Steward et al., 1993). Both victims (Berliner \& Conte, 1990) and perpetrators (Conte et al., 1989) have identified a gradual process whereby perpetrators employ successively inappropriate comments and increasingly inappropriate touches and behaviors so insidious that the abuse is often well under way before the child recognizes the situation as sexual or inappropriate. Strategies employed to gain the compliance of victims include the addition and withdrawal of inducements (attention, material goods, and privileges), misrepresentation of society's morals and standards and/ or the abusive acts themselves, and externalization of responsibility for the abuse onto the victim. Children are admonished that they (the child) will be judged negatively, blamed, and/or punished (Kaufman et al., 1996). In a review of the experimental and observational research examining the impact of threats upon disclosure, Lyon (1996) found that threats decrease the likelihood that children will self-disclose sexual abuse. Threats can take many forms including physical harm to the victim and/or their loved ones (Kaufman et al., 1996; Kelley et al., 1993), or forecasting negative or dire outcomes for the victim, their loved ones, and/or the perpetrator.

Studies provide conflicting findings on the relationship between disclosure and the method of coercion used to gain the child's compliance. Some have found no relationship between the method of coercion and disclosure (Arata, 1998; Lamb \& Edgar-Smith, 1994). Others have noted a temporal relationship between disclosure and the method used to gain the child's compliance. In one study, children subjected to aggressive strategies either told immediately (39\%) or refrained from reporting the abuse (43\%) (Gomes-Schwartz et al., 1990). Results of another study revealed that young children's disclosures of an adult's misdeeds were significantly suppressed when the request for secrecy was delivered in a more stern tone (Bussey, Lee, \& Richard, 1990, as cited in Bussey \& Grimbeek, 1995). In an archival study of children's disclosures of sexual abuse, findings revealed that delay to disclosure was nearly twice as long when records contained indications of physical aggression by the perpetrator against the victim or members of the victim's family (Paine \& Hansen, 2001).

To summarize, research indicates that most children are abused by someone known to them. The perpetrator is often in a position of authority and control over the child. Many perpetrators report they specifically target emotionally vulnerable children with whom they establish a trusting relationship. Establishment of a trusting relationship may extend to the victim's family as well, further complicating the child's ability to recognize the situation as abusive. The victimperpetrator relationship is often an emotionally significant one in which important needs are met for the child. Many child victims report ambivalent feelings for their perpetrator. Finally, perpetrators employ a variety of strategies, many of which are covert and insidious, to gain and maintain their victim's compliance and silence. The clinical and research literature reveal that these strategies effectively inhibit children from disclosing their abuse.

\section{Context of children's disclosures of sexual abuse}

\subsection{Latency to disclosure}

The clinical and research literature provide strong support for efficacy of the strategies employed by perpetrators to dissuade children from disclosing their sexual victimization. It is also testimony to the enormous difficulty of disclosure for child victims. 
Significant numbers of children deny their sexual victimization despite compelling evidence to the contrary (DiPietro et al., 1997; Lawson \& Chaffin, 1992; Sorenson \& Snow, 1991). Research suggests that less than one in four victims of CSA disclose immediately (GomesSchwartz et al., 1990; Kelley et al., 1993). Most children delay reporting their sexual victimization for months and many for years (Berliner \& Conte, 1990; Gomes-Schwartz et al., 1990; Kelley et al., 1993; Sorenson \& Snow, 1991). A mean delay of 3 years was found between the onset of sexual abuse and disclosure by children in a Canadian study (Oxman-Martinez, Rowe, Straka, \& Thibault, 1997). Lamb and Edgar-Smith (1994) found the mean age for first disclosure to be 18 years. This is a very significant finding given that the mean age of abuse onset for those in the sample was 8 years. In one study, $42 \%$ of adult males and $33 \%$ of adult females reporting a history of CSA indicated that they had never disclosed their victimization to anyone (Finkelhor et al., 1990). Among a sample of adjudicated adolescent male offenders, $67.7 \%$ of the youth reporting a history of sexual victimization indicated that they had never reported their abuse to anyone prior to engaging in the study (Brannon, Larson, \& Doggett, 1991). In a large, well-known study, 39\% of children with an objectively confirmed history of CSA had never reported their sexual victimization prior to presenting for treatment (Gomes-Schwartz et al., 1990). An additional $17 \%$ of the children had delayed reporting their sexual victimization for more than a year.

Researchers in an Australian study found remarkably higher rates (81\%) of disclosure by child victims than studies from the United States (Lynch et al., 1993). The sample was drawn from the Child Protection Units of two Children's Hospitals. These were designated referral centers for the evaluation of alleged CSA in a metropolitan area. In 57\% of these cases, the child had disclosed directly to a parent. Based upon comparison of participating and nonparticipating families, the researchers expressed concerns of sampling biases resulting from nonparticipation in studies of CSA. In this particular study, it was noted that more dysfunctional families were less likely to participate. Conditions in more functional homes, such as greater support and stability and/or other factors, may have favored disclosure. In addition, nonparticipating children were significantly older. Disclosure rates may have been somewhat inflated by the greater numbers of younger children in the study as research findings suggest older children disclose less frequently than younger children (Bybee \& Mowbray, 1993; Gomes-Schwartz et al., 1990).

\subsection{Disclosure setting: to whom, where, and why?}

Few of the studies available in the literature contained data on children's choice of confidant when initially disclosing their victimization. Only three provided complete data in this regard (Gomes-Schwartz et al., 1990; Lamb \& Edgar-Smith, 1994; Roesler \& Wind, 1994). One study provided data regarding the chosen confidant who did not note the initial confidant in cases in which multiple disclosures had been made (Arata, 1998). Of those children who disclose their sexual abuse, available data suggest most (41.8-57\%) make their initial disclosure to a parent or parent-figure (Berliner \& Conte, 1995; Gomes-Schwartz et al., 1990; Lamb \& Edgar-Smith, 1994; Lynch et al., 1993; Roesler \& Wind, 1994). Findings of one study revealed that children were about as likely to disclose to a parent (29\%) as they were to a friend (27\%) (Henry, 1994). 
One retrospective study (Arata, 1998) explored the disclosure histories of a sample of female undergraduates reporting a history of CSA. Forty percent of those reporting they disclosed their abuse during childhood indicated that they had told only one person (Arata, 1998). Twenty-four percent indicated that they had disclosed to two people, while $26 \%$ reported they told three people and $8 \%$ told four people. Most (58\%) chose their mother as their confidant. Fifty-four percent reported that they disclosed to a sibling or a friend, $36 \%$ to their father, and $26 \%$ told another adult.

It is widely believed that perceived support is an important factor mitigating children's willingness to disclose sexual abuse (Bussey \& Grimbeek, 1995; Furniss, 1991; Gomes-Schwartz et al., 1990; Summit, 1983). Among a population of children presenting to medical setting with physical complaints later diagnosed as a sexually transmitted disease, $57 \%$ of the children denied any history of sexual abuse (Lawson \& Chaffin, 1992). Children whose caretakers were "supportive" disclosed at a rate 3.5 times greater (63\%) than those whose caretakers were "nonsupportive" (17\%). Support was minimally defined as the caretakers willingness to accept the possibility that their child may have been sexually victimized and the absence of evidence of punishing or pressuring the child to deny abuse.

Elliott and Briere (1994) found children whose mothers were nonsupportive were significantly more likely to recant their initial disclosure of abuse than children whose mothers were supportive (15.4\% vs. 3.3\%). The subjects, 399 boys and girls between the ages of 8 and 15, were evaluated by a multidisciplinary team at an urban evaluation center. Their definition of support was very similar to that used by Lawson and Chaffin (1992). Elliott and Briere also found maternal support was predicted by a number of perpetrator, abuse, and family dynamic variables. Mothers were less likely to be supportive when the alleged perpetrator resided with them compared to those who lived elsewhere. Mothers were also less likely to be supportive when the victim reported more than one alleged perpetrator. Abuse variables found to be related to lower percentages of support included more than five reported incidents of abuse, abuse reported to have occurred for a year or more, and disclosure a year or more following cessation of the abuse. Family dynamics associated with less maternal support included a history of spousal abuse between the child's caretakers, a chemically dependent caretaker, a history of substantiated neglect of the child, or physical abuse of the child by a caretaker.

Children who have previously disclosed abuse may be more likely to disclose than those who have not during the context of a formal investigation (Gries et al., 1996; Keary \& Fitzpatrick, 1994) or medical examination (DiPietro et al., 1997). Keary and Fitzpatrick (1994) found that rates of disclosure during formal investigation varied significantly by prior disclosure history. Eighty-six percent of children with a history of prior disclosure disclosed during a formal investigation compared with $14 \%$ among the group with no history of prior disclosure. Gries et al. (1996) obtained disclosure rates comparable to those obtained by Keary and Fitzpatrick (1994). Ninety-three percent of those with a prior history of disclosure disclosed again during a formal assessment. DeVoe and Faller (1999) obtained similar, but slightly lower, rates of disclosure $(71 \%)$ among children with a history of prior disclosure. Results of many of the studies cited above indicate that some children require multiple interviews in order to disclose (DeVoe \& Faller, 1999; DiPietro et al., 1997; Gries et al., 1996; Keary \& Fitzpatrick, 1994). 
Findings of several studies suggest the disclosure process may differ by context (Bradley \& Wood, 1996). Studies conducted in psychotherapy settings (Gonzalez, Waterman, Kelly, McCord, \& Oliveri, 1993; Sorenson \& Snow, 1991) reveal significantly higher rates of recantation than studies conducted in child protection settings (Bradley \& Wood, 1996; Jones \& McGraw, 1987).

Despite the extensiveness of the present literature review, almost no information was found regarding children's disclosures of sexual abuse in contexts other than those identified above. There is significant evidence that many professionals who are mandated to report often fail to recognize maltreatment or report their suspicions (Kalichman, 1993; Warner \& Hansen, 1997). Results of a national incidence and prevalence study of child abuse and neglect revealed alarming numbers of professionals required to report abuse failed to do so (National Center on Child Abuse and Neglect (NCCAN), 1988). The study revealed that nearly half of all reports of child maltreatment are filed by professionals, primarily those in schools, mental health or social service agencies, hospitals, and day-care centers (NCCAN, 1988). However, across these agencies failure to report recognized cases of child maltreatment was substantial. Failure to report was highest in day-care centers ( $88 \%$ of cases), schools (76\%), and social service agencies $(70 \%)$, and lowest but still surprisingly high in mental health agencies (42\%) and hospitals (31\%). These findings raise serious concerns regarding the difficulties that children may experience disclosing in across all types of settings.

\subsection{Impetus for disclosure}

Few of the studies available in the literature provided quantitative data regarding the reason or trigger for children's disclosures of abuse. Sorenson and Snow (1991) retrospectively analyzed disclosure data in 630 cases of alleged CSA in which the authors were involved as therapists and/or evaluators from 1985 to 1989. Most of the children (80\%) were seen at a large nonprofit sexual abuse treatment facility, with the majority referred by police or protective services. The remainder were seen at the authors' private practice by private referral. Qualitative analyses of children's disclosures were conducted on a subset of 116 cases in which CSA was substantiated by compelling evidence (i.e., perpetrators confession, criminal conviction, medical evidence). A breakdown of the impetus for accidental and purposeful disclosure was provided. Exposure to the perpetrator $(28 \%)$ was the most common impetus for accidental disclosure across the age groups (i.e., 3-5, 6-9, 10-12, 13-17 years old). Exposure, in this sense, indicated that the child had recently spent time with an alleged or convicted perpetrator. Among children ages 3-9, the abuse was discovered through the child's inappropriate statement $(28 \%)$ or sexualized behavior (17\%). Purposeful disclosure was prompted by some type of educational program in $24 \%$ of the cases. Other triggers for purposeful disclosure included encouragement from peers $(10 \%)$ and proximity to perpetrator $(10 \%)$. Regarding the latter, disclosure was prompted by the departure of the perpetrator in some cases and by impending contact with the perpetrator in others. Anger was the most common impetus for purposeful disclosure among adolescents (58\%).

In one study of adults sexually abused as children, $47 \%$ of those reporting an initial disclosure during childhood indicated that they told in order to stop the abuse (Lamb \& Edgar-Smith, 
1994). Twenty-one percent indicated that they disclosed in order to obtain support. Some (10\%) reported that they disclosed in response to being asked or encouraged to do so. Another study of adults sexually abused as children offered detailed data regarding the impetus for disclosure (Roesler \& Wind, 1994). Unfortunately, the data did not distinguish the impetus for childhood disclosures from those made in adulthood.

\section{Motivational factors inhibiting self-disclosure}

Children contemplating the decision to disclose their sexual victimization encounter many significant fears and concerns (Furniss, 1991; Sauzier, 1989; Summit, 1983). Due to the covert nature of CSA, this ominous decision is borne by victims alone, without the advice, support, or encouragement of others. Within this void, the perpetrator may foretell or threaten that disclosure will result in dire outcomes or exploit the child's own fears regarding disclosure.

Numerous motivational factors have been identified as inhibiting children from disclosing their sexual victimization (Berliner \& Conte, 1990; Bussey \& Grimbeek, 1995; Finkelhor et al., 1990; Furniss, 1991; Gomes-Schwartz et al., 1990; Russell, 1986; Sorenson \& Snow, 1991; Summit, 1983). Most information regarding children's disclosures is based upon anecdotal accounts or peripheral findings of research on other aspects of CSA. Furthermore, much of the research in this area is based upon the retrospective reports of adults who were sexually abused as children (Arata, 1998; Finkelhor et al., 1990; Russell, 1986). For the purpose of the present discussion, these motivational factors influencing children's disclosures are grouped into four categories of concerns, those pertaining to (a) self, (b) family and loved ones, and (c) the perpetrator.

\subsection{Concerns pertaining to self}

Regardless of the type of abuse experienced by a child, most children feel responsible for their own abuse (Ney, Moore, McPhee, \& Trought, 1986). The dynamics of the abusive relationship and the insidious nature of the grooming process may lead victims to perceive themselves as willing participants in a "relationship" with the offender (Berliner \& Conte, 1990; Kaufman et al., 1996). Similarly, victims may perceive themselves as coconspirators, acting to maintain the secret of the abuse (Furniss, 1991; Summit, 1983). A retrospective study using a sample of female undergraduates suggests children who do not disclose their sexual victimization immediately may be more reluctant to disclose subsequent incidents of abuse (Arata, 1998). Victim's feelings of responsibility may be compounded by the intense feelings of shame and stigma associated with sexual abuse (Finkelhor, 1986; Furniss, 1991). Many children are reluctant to disclose their victimization for fear they will be blamed or judged negatively by others (Berliner \& Conte, 1995; Gomes-Schwartz et al., 1990; Sauzier, 1989). Children have related they were hesitant to break their promise to keep the abuse a secret (Bussey, Lee, \& Richard, 1990, reported in Bussey \& Grimbeek, 1995). In addition, as noted earlier, sexual stereotypes and concerns regarding homosexuality pose additional barriers to disclosure for male victims (Lynch et al., 1993; Reinhart, 1987; Summit, 1983; Watkins \& Bentovim, 1992). 
Many CSA victims have reported they delayed or refrained from disclosing their abuse because they feared they would not be believed (Furniss, 1991; Gomes-Schwartz et al., 1990; Summit, 1983). This fear is not only one instilled by perpetrators to maintain the child's silence, it is one that is borne out in reality for too many children. Results of two studies found nearly one child in ten who disclosed their sexual victimization reported their disclosure was received with disbelief (Berliner \& Conte, 1995; Gomes-Schwartz et al., 1990). The study by GomesSchwartz et al. (1990) revealed that children's initial disclosures failed to lead to any intervention in $17 \%$ of the cases. Lack of intervention was attributed to the disbelief of the confidant in approximately half of these cases. The remainder were attributed to the failure of the confidant to take any effective action to halt the abuse. Nearly 52\% of adult incest survivors responding to a questionnaire reported their abuse continued for a year or more following their disclosure to a parent (Roesler \& Wind, 1994). Results of a recent study of female college freshmen revealed that very few reported they received any type of legal or therapeutic intervention following their childhood disclosure of sexual abuse (Arata, 1998).

Finally, as indicated earlier, perpetrators often ask, bribe, and/or threaten victims to keep the abuse secret (Berliner \& Conte, 1990; Pipe \& Goodman, 1991; Kaufman et al., 1996). Personal threats to the victim may include threats of physical harm, punishment, and withdrawal of material goods, privileges, or affection.

\subsection{Concerns pertaining to family/loved ones}

Victims of CSA are often admonished that their family or loved ones will be hurt emotionally and/or physically if they divulge their abuse (Berliner \& Conte, 1990; Lyon, 1996; Sauzier, 1989, Summit, 1983). Not infrequently, the perpetrator imparts to the child a sense of responsibility for the safety and well-being of the perpetrator and/or the child's family. Disclosure is equated with devastating outcomes for the child's family, and/or the perpetrator. Conversely, the perpetrator conveys the message that the child has the power to keep their family and/or the perpetrator safe by maintaining the secret (Summit, 1983). Children fear that disclosure will result in the disruption or dissolution of their family through divorce, separation, or placement of the child and their siblings into foster care (Sauzier, 1989; Summit, 1983). In some cases, the child's fears and the perpetrator's threats are reinforced when the child discloses the abuse, or it is discovered in some other manner, and the child is pressured by family members and/or others to maintain the secret (Furniss, 1991; Rieser, 1991; Sorenson \& Snow, 1991; Summit, 1983).

\subsection{Concerns pertaining to the perpetrator}

As noted previously, the victim-perpetrator relationship is most often one that is familiar and close. Perpetrators tend to target emotionally needy, vulnerable children, exploiting not only their sexuality but their needs for attention and affection. As a result, victims often hold ambivalent and confusing feelings for their perpetrators. Some express concern for the physical and emotional well-being of the perpetrator should they disclose their sexual victimization (Berliner \& Conte, 1990; deYoung \& Lowry, 1992; Furniss, 1991; Sauzier, 1991; Summit, 1983). Perpe- 
trators sometimes threaten that they will commit suicide or otherwise harm themselves if the victim reveals the abuse. Victims have reported that they were reluctant to disclose their abuse for fear that their perpetrator would be incarcerated (Furniss, 1991; Russell, 1986; Summit, 1983). Widely recognized clinical explanations offered to account for the phenomenon of CSA victims protecting perpetrators include traumatic bonding (deYoung \& Lowry, 1992; Furniss, 1991) and accommodation to abuse dynamics (Summit, 1983, 1992). In reference to the dynamics in incest, deYoung and Lowry (1992) define traumatic bonding as "the evolution of emotional dependency between two persons of unequal power - an adult and a child, within a relationship characterized by periodic sexual abuse. The nature of this bond is distinguished by feelings of intense attachment, cognitive distortions, and behavioral strategies of both individuals that paradoxically strengthen and maintain the bond" (p. 167). Furniss (1991) has cited parallels between the victim-perpetrator relationship in cases of incest and the bizarre attachments that develop in some hostage-captor type situations. He notes that there is a "pseudonormal" interactional pattern between victims and perpetrators in which "... the camp guard and the terrorist are not only people who threaten life and integrity. They are at the time the perverted provider of life, maintenance and external care, and even of positive emotional attention" (Furniss, 1991, p. 30). Given these dynamics, "A primary punitive approach towards abusers is therefore a strong external factor for children to maintain secrecy and not to disclose" (Furniss, 1991, p. 24).

\section{Models of the disclosure process in CSA}

A review of the CSA literature reveals that few comprehensive models of the disclosure process have been proposed. Comprehensive models reviewed for the present paper include two stage-based models (Sorenson \& Snow, 1991; Summit, 1983, 1992), a social exchange explanation for the model proposed by Summit (Leonard, 1996), and a social cognitive model (Bussey \& Grimbeek, 1995). The latter two models are theoretically based. It should be noted that none of the models have been empirically validated. The present literature review failed to reveal any research, reviews, or commentaries regarding the social exchange and social cognitive models of disclosure cited above.

\subsection{Stage-based models of disclosure}

The Child Sexual Abuse Accommodation Syndrome (Summit, 1983) is the most widely recognized of these models. While the syndrome has not been empirically validated, it has been widely used by clinicians (Bussey \& Grimbeek, 1995). The syndrome has facilitated serious consideration by professionals of children's allegations of sexual abuse by illuminating obstacles to disclosure (Bussey \& Grimbeek, 1995). Highlights of the Child Sexual Abuse Accommodation Syndrome are provided below.

The proposed syndrome is comprised of five components: (a) secrecy; (b) helplessness; (c) entrapment and accommodation; (d) delayed, unconvincing disclosure; and (e) retraction. The first two components are identified as fundamental to the occurrence of sexual abuse while the remainder are noted to be complex sequential contingencies that may vary (Summit, 1983). 


\subsubsection{Secrecy}

In the vast majority of cases, sexual abuse occurs only when the child is alone with the offending adult. Regardless of the means by which the perpetrator invokes the child to keep the abuse secret, secrecy inherently conveys to the child that the abuse is something bad and dangerous. Perpetrators foretell that disclosure will result in dire outcomes for the victim, loved ones, and the perpetrator. The message imparted to the child is, "Maintaining a lie to keep the secret is the ultimate virtue, while telling the truth would be the greatest sin" (Summit, 1983, p. 185).

\subsubsection{Helplessness}

The expectation of others that children will self-protect and immediately disclose "ignores the basic subordination and helplessness of children within authoritarian relationships" (Summit, 1983, p. 182). They are expected to be obedient, even affectionate, with adults responsible for their care.

\subsubsection{Entrapment and accommodation}

Faced with a seemingly inescapable situation in which the child feels helpless, learning to accommodate to the sexual abuse is the only healthy alternative available. The means by which children accommodate include, but are not limited to, assuming personal responsibility for the abuse, adopting the distorted beliefs of the perpetrator, dissociating, and suppressing or repressing memories of the abuse.

\subsubsection{Delayed, unconvincing disclosure}

Most victims of ongoing abuse never disclose their victimization (Summit, 1983). When they do, delayed disclosure is the norm. The delayed and conflicted manner in which victims disclose casts doubt on their credibility.

\subsubsection{Retraction}

During the aftermath of disclosure, the child's anticipated fears regarding disclosure often become reality. Faced with others disbelief, lack of support, and the upheaval following disclosure, the child may retract the allegation of abuse in an attempt to undo the damage and restore equilibrium.

Acknowledging that Summit's model advanced our understanding of children's disclosure difficulties, Bussey and Grimbeek (1995) note that no quantitative data were offered to support the syndrome, which lacks a theoretical base. They note that this deficit was partially rectified by findings of an empirical study conducted by Sorenson and Snow (1991).

Sorenson and Snow (1991) retrospectively analyzed children's disclosures of sexual abuse in 116 cases substantiated by compelling evidence. Qualitative analyses of clinical notes, conversations, audio-and videotapes, and reports revealed four progressive components characteristic of children's disclosures: (a) denial; (b) disclosure; (c) recant; and (d) reaffirm. Seventy-two percent of the children examined denied, at some point, having been sexually abused. Most statements of denial occurred when the child was initially questioned by a concerned parent or 
adult or questioned during a formal investigation. Disclosures were observed to have a tentative and an active phase. During the tentative phase, children's disclosures were characterized as vague, partial, or vacillating. During the active phase, children provided a detailed, first-person account of their abuse. In only $11 \%$ of the cases did the child provide an active disclosure when first questioned about their victimization. Findings of another study revealed a progression from vague to more specific disclosures (Kelley et al., 1993). In the Sorenson and Snow study, children recanted their allegations in approximately $22 \%$ of the cases. However, $92 \%$ of those who recanted subsequently reaffirmed their allegations. While some children moved from denial to tentative and then active disclosure in one session, this process took months to occur for others.

A recent replication of the study by Sorenson and Snow (1991) yielded markedly different findings (Bradley \& Wood, 1996). Results of the study by Sorenson and Snow revealed that $72 \%$ of the children made a statement denying their abuse and $25 \%$ recanted a prior allegation at some point. Sorenson and Snow cited two other studies (Crewdson, 1988; Faller, 1988) in which rates of recantation ranged from $12 \%$ to $33 \%$. In sharp contrast, denial and recantation respectively occurred in only $6 \%$ and $4 \%$ of the cases analyzed by Bradley and Wood (1996). Bradley and Wood note that the latter findings are in opposition to stage or sequential disclosure models such as those proposed by Summit (1983) and Sorenson and Snow. Furthermore, they indicated that these findings suggest that the Child Sexual Abuse Accommodation Syndrome described by Summit appears to be infrequent among the types of cases seen by child protection agencies (Bradley \& Wood, 1996).

Bradley and Wood (1996) posited several possible reasons their findings differed so markedly from those of Sorenson and Snow (1991). A major factor is that the settings differed. Sorenson and Snow examined disclosure events in the context of psychotherapy. Bradley and Wood explored these events in the context of child protection or police interviews. The techniques of the interviewers and the social expectancies of the children in these settings may have differed. In addition, children may recant and reaffirm allegations over the course of therapy (Bradley \& Wood, 1996). Bradley and Wood cited results of an earlier study conducted by Jones and McGraw (1987) in a child protection agency yielded a recantation rate of $8 \%$, similar to the rate of 3-4\% obtained in their own study. In contrast, they noted that results of a study by Gonzalez et al. (1993) conducted in a therapy setting revealed a recantation rate of $27 \%$, comparable to the $22 \%$ reported by Sorenson and Snow. These comparisons suggest the disclosure process may differ by context (Bradley \& Wood, 1996).

In addition, sources of data used by Bradley and Wood (1996) differed from those used by Sorenson and Snow (1991). Data in the latter study were obtained from the psychotherapy notes of therapists supplemented by the therapist's personal recollections. The data in the study by Bradley and Wood were obtained from child protective service (CPS) files. Due to time constraints and legal concerns inherent in the investigatory process, children's denials, recantations, or reluctance to disclose may have been systematically underreported (Bradley \& Wood, 1996).

Perhaps the disclosure phenomenon observed by earlier clinicians and researchers (Sauzier, 1989; Sorenson \& Snow, 1991; Summit, 1983) have changed as a result of advancements in the 
field of CSA. Bradley and Wood (1996) noted that the children may have felt less pressure to recant because adults have become less skeptical as a result of increased public awareness of CSA. It appears equally plausible that the lower rates of denial and retraction obtained by Bradley and Wood may also be attributed to advances in interviewing techniques, case management, and legal interventions in cases of CSA.

\subsection{Social exchange model of disclosure}

Leonard (1996) has offered an interesting analysis of the Child Sexual Abuse Accommodation Syndrome (Summit, 1983) from the perspective of social exchange theory. Exchange theories are based on the guiding premise that "individuals pursue those social relationships and interactions in which, based on perceptions of rewards and costs, they get the best payoffs, or the greatest reward for the least cost" (Leonard, 1996, p. 107). Conversely, individuals avoid exchange relations that are high in cost to them. The potential for the use or abuse of power is intrinsic to the exchange perspective (Leonard, 1996). In this vein, Leonard notes that Blau (1964) proposed the definition of power be expanded to read that "it is the ability of persons or groups to impose their will on others despite resistance through deterrence either in the forms of withholding regularly supplied rewards or in the form of punishment, both being negative sanctions" (Blau, 1964, p. 117). Applying principles of cost and rewards to each of the five components of the CSA Accommodation Syndrome, Leonard attempts to demonstrate that each component reflects the least unprofitable of the limited options child victims perceive are available. He extends this theory to perpetrators and members of the victim's family. His application of exchange theory to one component of the CSA Accommodation Syndrome (i.e., entrapment and accommodation) is offered to illustrate. Subjected to repeated sexual abuse without intervention, the child victim holds little hope for rescue or a timely end to the abuse (entrapment). From the perspective of exchange-equity theory, an individual in an inequitable relationship

with another grows increasingly distressed as the inequity mounts. "In order to reduce the distress, an individual can restore actual equity (rarely an option for a child in an abusive dyad) or psychological equity" (Leonard, 1996, p. 113). Psychological equity is achieved by distorting reality in order to convince themselves that the treatment they are receiving is deserved (accommodation) (Leonard, 1996). Research has demonstrated that under the right conditions, both "exploiters" and their victims are capable of convincing themselves that even the most inequitable exchanges are fair (Leonard, 1996; Walster, 1978; Walster, Walster, \& Berscheid, 1978). The perpetrator conveys the notion to the child that being good means being available and compliant. "Frequently, there is an implicit or explicit promise of reward to the child for being 'good,' such as the preservation of the home, and/or the protection of siblings from sexual abuse" (Leonard, 1996, p. 113).

\subsection{Social-cognitive model}

Bussey and Grimbeek (1995) have proposed a comprehensive model of the disclosure process in CSA derived from social-cognitive theory. Citing the work of Bandura $(1986,1989)$, 
they note that social-cognitive theory advances a "dynamic interactional model in which disclosure is multidetermined" (Bussey \& Grimbeek, 1995, p. 175). The model posits that there are four sociocognitive determinants of disclosure: attention; retention; production; and motivation. They note that these four component processes were initially proposed by Bandura to account for children's observational learning as bystanders. Disclosure may be inhibited when children "have not paid sufficient attention to the event (attention processes), they are unable to remember it in sufficient detail (retention processes), they are unable to adequately communicate about the event (production processes), or they are unwilling to report it (motivation processes)" (Bussey \& Grimbeek, 1995, p. 197-198).

The social-cognitive model of disclosure purports that "the course of disclosure will vary according to children's cognitive capabilities, social experience, and the particular situation in which they find themselves" (Bussey \& Grimbeek, 1995, p. 186). Their model offers a theoretical basis for research findings that reveal lower rates of disclosure among older children. From a cognitive perspective, older children are better able to report their abuse due to increased attentional, retentional, and production skills. However, with increased cognitive abilities and social experience, children become more aware of the costs and benefits of disclosure. For these reasons, it is anticipated that children's disclosure will be more self-regulated as they mature (Bussey \& Grimbeek, 1995).

The models reviewed in this section provide similar and complementary explanations of children's disclosures of sexual abuse from different theoretical perspectives or a clinical perspective. The only significant area of contention evident is whether disclosure is a developmental (or stage) process. Further research is needed to resolve conflicting findings in this area. Since his initial (1983) paper describing the Child Sexual Abuse Accommodation Syndrome, Summit (1992) has stressed that the syndrome was never intended to imply disclosure occurs in an invariable sequence.

\section{Ancillary and analogue research on secrecy and disclosure}

There is a body of ancillary research on secrecy in children and adults relevant to children's disclosures of sexual abuse (Kelly \& McKillop, 1996; Lane \& Wegner, 1995; Last \& AharoniEtzioni, 1994; Wegner, 1989). Likewise, there are a number of analogue studies that illustrate the disclosure difficulties of children in general (Clarke-Stewart, Thompson, \& Lapore, 1989; Peters, 1991; Saywitz, Goodman, Nicholas, \& Moan, 1989). These two bodies of research reveal that many of the disclosure concerns of sexually abused children are not unique to sexual abuse. They simultaneously provide a contrast by which to gauge the magnitude of disclosure difficulties faced by sexually abused children.

Last and Aharoni-Etzioni (1994) explored reasons a nonclinical population of children identified for keeping a "very personal" secret. Some of the motivations identified parallel those identified by child victims of sexual abuse. The subjects in this study were 180 Israeli boys and girls in the 3rd, 5th, and 7th grade. In an analysis of the substance and dynamics of secrets elicited from the children, Last and Aharoni-Etzioni observed four main categories of motivations for secrecy. These were: shame; fear of punishment; exclusiveness (privacy, fear of losing 
exclusive possession or accessibility); and empathy (including the need to avoid hurting others or breaking a promise to keep a secret). A fifth category, residual, included the need to avoid uneasiness.

Faller (1994) has made compelling points regarding the disclosure difficulties experienced by some sexually abused children. Many analogue studies fail to incorporate important characteristics pertaining to the dynamics of sexual abuse and disclosure (Faller, 1994). These dynamics include the child's shame related to their involvement in the activity, admonitions and threats to prevent disclosure, and the child's anticipation of dire outcomes should he or she disclose the abuse. In reference to these analogue studies (e.g., Clarke-Stewart et al., 1989; Peters, 1991; Saywitz et al., 1989), Faller has noted, "When mild versions of these elements are included in the research paradigm, children don't talk" (p. 116).

Analogue studies reveal children's reluctance to talk about their private parts and intrusive experiences. Researchers in one study compared the reports of 5-and 7-year-old girls having scoliosis exams to those having genital and anal exams (Saywitz et al., 1989). When asked an open-ended question about their doctor visit, all of the children having the scoliosis exam spontaneously mentioned having their back touched. Few of the children having a genital exam $(22 \%)$ or anal exam $(11 \%)$ reported being touched in those areas.

Analogue studies also reveal children's hesitance to disclose the misdeeds of adults. When asked by a "janitor" to conceal that he had been playing with toys instead of working, $64 \%$ of the 5-and 6-year-old children participating in the study kept his secret (Clarke-Stewart et al., 1989). Findings of a different study indicate that children frequently conceal the misdeeds of an adult even when they are not asked to do so. Minutes after witnessing a theft, $58 \%$ of the child subjects declined to identify the thief from five other adults (Peters, 1991). Results of another study revealed that young children's disclosures of an adult's misdeeds were significantly suppressed when the request for secrecy was delivered in a more stern tone (Bussey, Lee, \& Richard, 1990, as cited by Bussey \& Grimbeek, 1995). When the adult male asked the child in a normal tone to keep his transgression a secret, $14 \%$ of 3 -year-olds and $43 \%$ of 5 -year-olds did not disclose the transgression. When the request was made in a stern tone $43 \%$ of 3 -year-olds and $71 \%$ of 5-year-olds maintained the secret by refusing to answer questions about the adult's transgression or denying that the transgression had occurred. Bussey and Grimbeek (1995) discuss findings of several studies which indicate that children become increasingly selective and learn to regulate disclosure with increased cognitive competence and social experience. According to Bussey and Grimbeek, "They learn to inhibit their disclosure of events, particularly events that they anticipate others might respond to in an unfavorable manner, even when not explicitly asked not to disclose" (p. 183).

This research illuminates the tremendous obstacles that child victims of sexual abuse must surmount to disclose their abuse. Sexually abused children contemplating disclosure are often faced with the very real possibility of sweeping consequences in many areas of their life. A medical examination of one's genitals cannot compare with the shame, stigma, and feelings of responsibility experienced by victims of sexual assault. The gravity of sexual assault far exceeds that of the adult's misdeeds, which children were hesitant to disclose in the analogue 
studies above. The threat to a child of tattling on an unknown adult pales in comparison to the ominous threat of exposing a sexual assault by an individual with whom the child has a significant relationship.

A body of research literature reveals similarities between the disclosure concerns of adults bearing negative personal secrets and the disclosure concerns of sexually abused children (see Kelly \& McKillop, 1996 for a review). Most adults keep personal secrets out of fear of the real or imagined consequences of disclosure (Wegner, 1989). The feared consequences of disclosure commonly identified by adults bearing personal secrets include shame, lack of support, rejection, fear that they will not be believed, and fear that others will be upset by the information to be disclosed (Kelly \& McKillop, 1996).

The secrecy literature suggests the costs of keeping personal secrets can be significant. Lane and Wegner (1995) have proposed a preoccupation model of secrecy in which the act of keeping a secret triggers a series of cognitive processes that result in obsessive preoccupation with the secret thought. Using four research paradigms, the researchers found positive correlations between thought suppression and intrusive thoughts in a task that required adult participants to keep a word secret (Lane \& Wegner, 1995). Of relevance to CSA, the main elements of this model are symptoms characteristic of posttraumatic stress disorder (i.e., suppression and intrusion of unwanted thoughts). Results of a study on the effects of childhood disclosure of sexual abuse on the subsequent mental health of the subject population (female undergraduates) revealed findings consistent with those described above. While disclosure was not associated with overall current mental health functioning, disclosure was positively correlated with fewer intrusive and avoidant symptoms (Arata, 1998). In a review of theories and empirical findings regarding the consequences of revealing personal secrets, Kelly and McKillop (1996) note that there is some experimental evidence and a fair amount of correlational evidence that suggests the greater the resources one employs to inhibit information, the greater the probability of stress-related physical and psychological problems. For children who are unable to disclose their sexual victimization, the consequences of nondisclosure include possible continued victimization, absence of support, and failure to receive legal and therapeutic interventions.

\section{Conclusion}

The nature and dynamics of CSA make it exceedingly difficult for children to disclose their victimization. Research consistently indicates that most children either maintain the secret or delay reporting for significant periods of time (Berliner \& Conte, 1990; Gomes-Schwartz et al., 1990; Kelley et al., 1993; Sorenson \& Snow, 1991). Furthermore, research reveals that disturbing numbers of children deny their sexual victimization even in the face of compelling evidence to the contrary (DiPietro et al., 1997; Lawson \& Chaffin, 1992; Sorenson \& Snow, 1991).

Sexually abused children face many imposing obstacles to disclosure. In addition to the dependency and vulnerability inherent to childhood, these barriers include cognitive and developmental factors (Bussey \& Grimbeek, 1995; Saywitz, Nathanson, \& Snyder, 1993), strategies 
employed by perpetrators to gain and maintain compliance and silence (Elliott et al., 1995; Conte et al., 1987; Kaufman et al., 1996), and internal and external factors that lead children to feel guilty and/or responsible for the abuse (Ney et al., 1986; Sauzier, 1989; Summit, 1983). Many child victims fear they will not be believed or helped (Gomes-Schwartz et al., 1990; Summit, 1983). Research indicates that these fears are borne out in reality for too many children, resulting in lack of legal and/or therapeutic intervention (Arata, 1998; Berliner \& Conte, 1995; Gomes-Schwartz et al., 1990). Though limited, the clinical and research literature on CSA and disclosure reveals that disabled children (Goldman, 1994; Saywitz, 1993) and those belonging to cultural or ethnic minorities (Futa et al., in press; Kazarian \& Kazarian, 1998; Toukmanian \& Brouwers, 1998) are faced with even greater obstacles to disclosure.

Motivational factors inhibiting disclosure include fears for the physical and emotional wellbeing of self, loved ones, and, in some instances, even the perpetrator (Berliner \& Conte, 1990; Lyons, 1996; Sauzier, 1989; Summit, 1983). The victim-perpetrator relationship in most cases of CSA is a significant one that meets important needs for the child. Consequently, children often hold ambivalent feelings for the individual perpetrating the abuse (Berliner \& Conte, 1990; Furniss, 1991; Summit, 1983). Due to the covert nature of CSA, children contemplating disclosure face this ominous decision alone; without the advice, support, or encouragement of others.

Despite increased public awareness and mandatory reporting statutes, research indicates that many adults still fail to report suspected abuse (Dhooper et al., 1991). Prevention programs improve children's knowledge of behaviors that constitute sexual abuse and prompt some to disclose past abuse (Daro, 1994; MacMillan, MacMillan, Offord, Griffith, \& MacMillan, 1994). Their efficacy in providing children with skills to prevent sexual victimization has yet to be established, however (MacMillan et al., 1994). Concerns have been expressed that with the exception of stressing that victims are never to blame, prevention programs largely fail to address motivational factors that make it difficult for children to tell (Daro, 1994; Hazzard, Webb, Kleemeier, Angert, \& Pohl, 1991). These issues underscore the importance of facilitating children's disclosures of sexual abuse and ameliorating impediments to early disclosure. Prompt disclosure is second only to prevention in the goal of protecting children from sexual abuse.

Although disclosure status (i.e., disclosure vs. nondisclosure) is an important measure of a child's reluctance to reveal the secret of their abuse, it is a gross, dichotomous measure. Findings of one recent study revealed that the length of delay to disclosure is a more sensitive measure with the capacity to detect degrees of reluctance and disclosure differences (Paine \& Hansen, 2001). The latency between abuse onset and disclosure is a critical issue to be addressed in any study that examines children's disclosures of sexual abuse. It may also prove to be an important measure of the efficacy of prevention efforts.

Despite a wealth of clinical literature on motivational factors that inhibit children from disclosing sexual abuse, little quantitative data are available. Very few studies provide data on the impetus for disclosure or circumstances that facilitate disclosure. Research on age and gender differences in children's disclosure of sexual abuse is lacking. Moreover, little is known about cultural differences in disclosure (Fontes, 1993). Research on these factors could be used to tailor clinical and child protective interventions to better address victim's needs and their disclosure concerns. 
It is not enough to educate children to recognize behaviors that constitute sexual abuse and instruct them to tell. Those seeking to prevent or halt CSA must acknowledge the real and formidable barriers to disclosure. Parents, individuals working with children, and the public in general must be educated regarding the disclosure process in CSA and common barriers to disclosure. This might serve to increase support for children making an active disclosure and decrease the likelihood of negative reactions to the tentative disclosures of many children. Older children might benefit from education on the covert tactics employed by sexual perpetrators. Incorporating common strategies employed by perpetrators into prevention programs may help to immunize children against these ploys. Likewise, educating parents and the public on the methods by which perpetrators operate may increase recognition of perpetrators in action prior to, or during the early phases of, a child's abuse.

\section{References}

Arata, C. M. (1998). To tell or not to tell: current functioning of child sexual abuse survivors who disclosed their victimization. Child Maltreatment, 3, 63-71.

Bandura, A. (1986). Social foundation of thought and action: a social cognitive theory. Englewood Cliffs, NJ: Prentice-Hall.

Bandura, A. (1989). Social cognitive theory. In: R. Vasta (Ed.), Annals of child development: six theories of child development (vol. 6, pp. 1-60). Greenwich, CT: JAI.

Berliner, L., \& Conte, J. R. (1990). The process of victimization: the victims' perspective. Child Abuse and Neglect, 14, 29-40.

Berliner, L., \& Conte, J. R. (1995). The effects of disclosure and intervention on sexually abused children. Child Abuse and Neglect, 19, 371-384.

Blau, P. M. (1964). Exchange and power in social life. New York: Wiley.

Bolton, F. G., Morris, L. A., \& MacEachron, A. E. (1989). Males at risk: the other side of child sexual abuse. Newbury Park, CA: Sage Publications.

Bradley, A. R., \& Wood, J. M. (1996). How do children tell?: the disclosure process in child sexual abuse. Child Abuse and Neglect, 20, 881-891.

Brannon, J. M., Larson, B., \& Doggett, M. (1991). Peer counseling strategies: facilitating self-disclosure among sexually victimized juvenile offenders. Journal of Addictions and Offender Counseling, 11, 51-58.

Browning, D., \& Boatman, B. (1977). Incest: children at risk. American Journal of Psychiatry, 134, 69-72.

Budin, L. E., \& Johnson, C. F. (1989). Sex abuse prevention programs: offenders' attitudes about their efficacy. Child Abuse and Neglect, 13, 77-87.

Bussey, K., \& Grimbeek, E. J. (1995). Disclosure processes: issues for child sexual abuse victims. In: K. J. Rotenberg (Ed.), Disclosure processes in children and adolescents (pp. 166-203). Cambridge: Cambridge Univ. Press.

Bybee, D., \& Mowbray, C. T. (1993). An analysis of allegations of sexual abuse in a multi-victim day-care center case. Child Abuse and Neglect, 17, 767-783.

Campis, L. B., Hebden-Curtis, J., \& Demaso, D. R. (1993). Developmental differences in detection and disclosure of sexual abuse. Journal of the American Academy of Child and Adolescent Psychiatry, 32, 920-924.

Christiansen, J. R., \& Blake, R. H. (1990). The grooming process in father-daughter incest. In: A. L. Horton, B. L. Johnson, L. M. Roundey, \& D. Williams (Eds.), The incest perpetrator: a family member no one wants to treat (pp. 88-98). Newbury Park, CA: Sage Publications. 
Clarke-Stewart, A., Thompson, T., \& Lapore, S. (1989). Manipulating children's interpretations throughout interrogation. In: G. Goodman (Chair), Can children provide accurate eyewitness reports? Symposium presented at the meeting of the Society for Research in Child Development, Kansas City, MO.

Conte, J. R., \& Schuerman, J. (1987). Factors associated with an increased impact of child sexual abuse. Child Abuse and Neglect, 11, $201-211$.

Conte, J. R., Wolfe, S., \& Smith, T. (1989). What sexual offenders tell us about prevention strategies. Child Abuse and Neglect, 13, $293-301$.

Crewdson, J. (1988). By silence betrayed. New York: W.W. Norton.

Daro, D. A. (1994). Prevention of child sexual abuse. The Future of Children, 4, 199-223.

deYoung, M., \& Lowry, J. A. (1992). Traumatic bonding: clinical implications in incest. Child Welfare, LXXI, 165-175.

DeVoe, E. R., \& Faller, K. C. (1999). The characteristics of disclosure among children who may have been sexually abused. Child Maltreatment, 4, 217-227.

Dhooper, S. S., Royce, D. D., \& Wolfe, L. C. (1991). A statewide study of the public attitudes toward child abuse. Child Abuse and Neglect, 15, 37-44.

DiPietro, E. K., Runyan, D. K., \& Fredrickson, D. D. (1997). Predictors of disclosure during medical evaluation for suspected sexual abuse. Journal of Child Sexual Abuse, 6 (1), 133-142.

Elliott, D. M., \& Briere, J. (1994). Forensic sexual abuse evaluations of older children: disclosures and symptomatology. Behavioral Sciences and the Law, 12, 261-277.

Elliott, M. (1993). What survivors tell us - an overview. In: M. Elliott (Ed.), Female sexual abuse of children: the ultimate taboo (pp. 5-14). Essex, England: Longman.

Elliott, M., Browne, K., \& Kilcoyne, J. (1995). Child sexual abuse prevention: what offenders tell us. Child Abuse and Neglect, 19, $579-594$.

Faller, K. C. (1985). Unanticipated problems in the United States child protection system. Child Abuse and Neglect, 9, 63-69.

Faller, K. C. (1988). Criteria for judging the credibility of children's statements about their sexual abuse. Child Welfare, 68, 389-401.

Faller, K. C. (1989). Characteristics of a clinical sample of sexually abused children: how boy and girl victims differ. Child Abuse and Neglect, 13, 281-291.

Faller, K. C. (1994). Commentary of the children forgotten in the interdisciplinary consensus statement. Journal of Child Sexual Abuse, 3 (4), 115 -121.

Finkelhor, D. (1986). A sourcebook on child sexual abuse. Beverly Hills: Sage Publications.

Finkelhor, D., Hotaling, G., Lewis, I. A., \& Smith, C. (1990). Sexual Abuse in a national survey of adult men and women: prevalence, characteristics, and risk factors. Child Abuse and Neglect, 14, 19 -28.

Fontes, L. A. (1993). Disclosures of sexual abuse by Puerto Rican children: oppression and cultural barriers. Journal of Child Sexual Abuse, 2 (1), 21-35.

Furniss, T. (1991). The multi-professional handbook of child sexual abuse: integrated management, therapy, and legal intervention. London: Routledge.

Futa, K. T., Hsu, E., \& Hansen D. J. Child sexual abuse in Asian American families: an examination of cultural factors that influence prevalence, identification, and treatment. Clinical Psychology: Science and Practice (in press).

German, K. E., Habenicht, D. J., \& Futcher, W. G. (1990). Psychological profile of the female adolescent incest victim. Child Abuse and Neglect, 14, 238-429.

Goldman, R. L. (1994). Children and youth with intellectual disabilities: targets for sexual abuse. International Journal of Disability, Development and Education, 41 (2), 89-102.

Gomes-Schwartz, B., Horowitz, J. M., \& Cardarelli, A. P. (1990). Child sexual abuse: the initial effects. Newbury Park, CA: Sage. 
Gonzalez, L. S., Waterman, J., Kelly, R. J., McCord, F., \& Oliveri, M. K. (1993). Children's patterns of disclosures and recantations of sexual and ritualistic abuse allegations in psychotherapy. Child Abuse and Neglect, 17, 281-289.

Gries, L. T., Goh, D. S., \& Cavanaugh, J. (1996). Factors associated with disclosure during child sexual abuse assessment. Journal of Child Sexual Abuse, 5 (3), $1-19$.

Groth, A. N., Longo, R. E., \& McFadin, J. B. (1982). Undetected recidivism among rapists and child molesters. Crime and Delinquency, 28, 450-458.

Hansen, D. J., Bumby, K. M., Lundquist, L. M., Chandler, R. M., Le, P. T., \& Futa, K. T. (1997). The influence of case and professional variables on the identification and reporting of child maltreatment: a study of licensed psychologists and certified masters social workers. Journal of Family Violence, 12, 313-332.

Hazzard, A., Webb, C., Kleemeier, C., Angert, L., \& Pohl, J. (1991). Child sexual abuse prevention: evaluation and one-year follow-up. Child Abuse and Neglect, 15, $123-138$.

Hecht, D. A., \& Hansen, D. J. (1999). Adolescent victims and intergenerational issues in sexual abuse. In: V. B. Van Hasselt, \& M. Hersen (Eds.), Handbook of psychological approaches with violent criminal offenders: contemporary strategies and issues (pp. 303 -328). New York: Plenum.

Henry, J. (1994). System intervention trauma to child sexual abuse victims following disclosure. Journal of Interpersonal Violence, 12, 499-512.

Jennings, K. (1993). Female child molestation: a review of the literature. In: M. Elliott (Ed.), Female sexual abuse of children: the ultimate taboo (pp. 241-257). Essex, England: Longman.

Jones, D. P. H., \& McGraw, J. M. (1987). Reliable and fictitious accounts of sexual abuse in children. Journal of Interpersonal Violence, 2, 27-45.

Kalichman, S. C. (1993). Mandated reporting of suspected child abuse: ethics, law, and policy. Washington, DC: American Psychological Association.

Kaufman, K. L., Hilliker, D. R., \& Daleiden, E. (1996). Subgroup differences in the modus operandi of adolescent sexual offenders. Child Maltreatment, 1, $17-24$.

Kazarian, S. S., \& Kazarian, L. Z. (1998). Cultural aspects of family violence. In: S. S. Kazarian, \& D. R. Evans (Eds.), Cultural clinical psychology: theory, research and practice (pp. 316-347). Oxford: Oxford Univ. Press.

Keary, K., \& Fitzpatrick, C. (1994). Children's disclosure of sexual abuse during formal investigation. Child Abuse and Neglect, 18, 543-548.

Kelley, S. J., Brant, R., \& Waterman, J. (1993). Sexual abuse of children in day care centers. Child Abuse and Neglect, 17, 71-89.

Kelly, A. E., \& McKillop, K. J. (1996). Consequences of revealing personal secrets. Psychological Bulletin, $120,450-465$.

Kendall-Tackett, K. A., Williams, L. M., \& Finkelhor, D. (1993). Impact of sexual abuse on children: a review and synthesis of recent empirical studies. Psychological Bulletin, 113, 164-180.

Lamb, S., \& Edgar-Smith, S. (1994). Aspects of disclosure mediators of outcome of childhood sexual abuse. Journal of Interpersonal Violence, 9, 307-326.

Lane, J. D., \& Wegner, D. M. (1995). The cognitive consequences of secrecy. Journal of Personality and Social Psychology, 69, 237-253.

Last, U., \& Aharoni-Etzioni, A. (1994). Secrets and reasons for secrecy among school-aged children: developmental trends and gender differences. The Journal of Genetic Psychology, 156, 191-203.

Lawson, L., \& Chaffin, M. (1992). False negatives in sexual abuse disclosure interviews. Incidence and influence of caretaker's belief in abuse in cases of accidental abuse discovery by diagnosis of STD. Journal of Interpersonal Violence, 7, $532-542$.

Leonard, E. D. (1996). A social exchange explanation for the Child Sexual Abuse Accommodation Syndrome. Journal of Interpersonal Violence, 11, 107-117. 
Ligezinska, M., Firestone, P., Manion, I. G., McIntyre, J., Ensom, R., \& Wells, G. (1996). Children's emotional and behavioral reactions following the disclosure of extrafamilial sexual abuse: initial effects. Child Abuse and Neglect, 20, 111-125.

Lynch, D. L., Stern, A. E., Oates, K., \& O’Toole, B. I. (1993). Who participates in child sexual abuse research? Journal of Child Psychology and Psychiatry, 34, 935-944.

Lyon, T. (1996). The effect of threats on children's disclosure of sexual abuse. The APSAC Advisor, 9 (3), $9-15$.

MacMillan, H. L., MacMillan, J. H., Offord, D. R., Griffith, L., \& MacMillan, A. (1994). Primary prevention of child sexual abuse: a critical review: part II. Journal of Child Psychology and Psychiatry, 35, 857-876.

Mendelsohn, C. (1994). Child sexual abuse: the relation between victim disclosure and familial closeness of perpetrator. Doctoral dissertation, Rutgers University. Dissertation Abstracts Online No. 01367090.

Mian, M., Wehrspann, W., Klajner-Diamond, H., Labaron, D., \& Winder, C. (1986). Review of 125 children 6 years of age and under who were sexually abused. Child Abuse and Neglect, 4, 223-229.

Mordock, J. B. (1996). Treatment of sexually abused children: interview technique, disclosure, and progress in therapy. Journal of Child Sexual Abuse, 5 (4), 105-121.

Muntarbhorn, V. (1996). Sexual exploitation of children. New York: United Nations Publication.

National Center on Child Abuse and Neglect (NCCAN) (1988). Study of national incidence and prevalence of child abuse and neglect: 1988. Washington, DC: US Department of Health and Human Services.

Ney, P. G., Moore, C., McPhee, M., \& Trought, P. (1986). Child abuse: a study of the child's perspective. Child Abuse and Neglect, 10, $511-518$.

Oxman-Martinez, J., Rowe, W. S., Straka, S. M., \& Thibault, Y. (1997). La baisse d'abuse sexuels. Revue quebecoise de Psychologie, 18 (3), 77-90.

Paine, M. L., \& Hansen, D. J. (2001). Children's self-disclosure of sexual abuse: effects of victim, perpetrator, and abuse characteristics (submitted for publication).

Peters, D. (1991). The influence of stress and arousal on the child witness. In: J. Doris (Ed.), The suggestibility of children's recollections (pp. 60-76). Washington, DC: American Psychological Association.

Pipe, M. E., \& Goodman, G. S. (1991). Elements of secrecy: implications for children's testimony. Behavioral Sciences and the Law, 9, 33-41.

Pope, K., Tabachnick, B., \& Keith-Spiegel, P. (1987). Ethics of practice: the beliefs and behaviors of psychologists as therapists. American Psychologist, 42, $993-1006$.

Reinhart, M. (1987). Sexually abused boys. Child Abuse and Neglect, 11, 229-235.

Rieser, M. (1991). Recantation in child sexual abuse cases. Child Welfare, 612-613.

Roesler, T. A., \& Wind, T. W. (1994). Telling the secret: adult women describe their disclosures of incest. Journal of Interpersonal Violence, 9, 327-338.

Russell, D. (1986). The secret trauma. New York: Basic Books.

Sauzier, M. (1989). Disclosure of child sexual abuse: for better or worse. Psychiatric Clinics of North America, 12, 455-469.

Saywitz, K., Goodman, G., Nicholas, E., \& Moan, S. (1989). Children's memory for a genital exam: implications for sexual abuse cases. In: Goodman, G. (Chair), Can children provide accurate eyewitness reports? Symposium presented at the meeting of the Society for Research in Child Development, KS City, MO.

Saywitz, K., Nathanson, R., \& Snyder, L. (1993). Credibility of child witnesses: the role of communicative competence. In L. Synder, \& K. Saywitz (Eds.), Child abuse and communicatively disordered children: special issue, topics in language disorders, 13 (4), $59-78$.

Singer, M. I., Hussey, D., \& Strom, K. J. (1992). Grooming the victim: an analysis of a perpetrator's seduction letter. Child Abuse and Neglect, 16, 877-886.

Sorenson, T., \& Snow, B. (1991). How children tell: the process of disclosure in child sexual abuse. Child Welfare, LXX, 3-15. 
Steward, M. S., Bussey, K., Goodman, G. S., \& Saywitz, K. J. (1993). Implications of developmental research for interviewing children. Child Abuse and Neglect, 17, 25-37.

Sullivan, P. M., \& Knutzon, J. F. (2000). Maltreatment and disabilities: a population-based epidemiological study. Child Abuse and Neglect, 24, 1257-1273.

Summit, R. (1983). Child Sexual Abuse Accommodation Syndrome. Child Abuse and Neglect, 11, 229 -235.

Summit, R. (1992). Abuse of the Child Sexual Abuse Accommodation Syndrome. Journal of Child Sexual Abuse, 1 (4), $153-163$.

Swoboda, J. S., Elwork, A., Sales, B. D., \& Levine, D. (1987). Knowledge and compliance with privileged communication and child-abuse-reporting laws. Professional Psychology, 9, 448-458.

Toukmanian, S. G., \& Brouwers, M. C. (1998). Cultural aspects of self-disclosure and psychotherapy. In: S. S. Evans, \& D. R. Evans (Eds.), Cultural clinical psychology: theory, research and practice (pp. 106-124). Oxford: Oxford Univ. Press.

Violato, C., \& Genius, M. (1993). Problems of research in male child sexual abuse: a review. Journal of Child Sexual Abuse, 2 (3), $33-54$.

Walster, E. (1978). Equity theory and attraction. In: E. Berscheid, \& E. H. Walster (Eds.), Interpersonal attraction (2nd ed.) (pp. 125-146). Reading, MA: Addison-Wesley.

Walster, E., Walster, G. W., \& Berscheid, E. (1978). Equity: theory and research. Boston: Allyn and Bacon.

Warner, J. E., \& Hansen, D. J. (1997). Identification and reporting of child abuse by medical professionals: a critical review. Child Abuse and Neglect, 18, 11-25.

Warner-Kearney, D. (1987). The nature of grooming behavior used by sexual offenders in father -daughter incest. Paper presented at the Western Criminology Association, Las Vegas, NV.

Watkins, B., \& Bentovim, A. (1992). The sexual abused of male children and adolescents: a review of current research. Journal of Child Psychology and Psychiatry, 33, 197-248.

Wegner, D. M. (1989). White bears and other unwanted thoughts. New York: Guilford. 